\title{
ÁGUA QUASE TUDO....E CLORETO DE SÓDIO: PURIFICAÇÃO DO CLORETO DE SÓDIO
}

\author{
Clementina Teixeira*, Vânia André, Sílvia Chaves, \\ Hermínio Diogo, Nuno Lourenço, Fillipe Meneses
}

O sal está ligado à nossa situação geográfica e, por isso, à nossa vivência, história, cultura, recursos, aos nossos salários, aos nossos negócios em tempos de empreendorismo. Por isso resolvemos purificá-lo. De uma forma simples, num infantário "na sala dos cinco anos", o infantário da APIST (Associação de Pessoal do Instituto Superior Técnico). De uma forma mais elaborada, nos Laboratórios de Química do DEQB (Departamento de Eng. Química e Biológica). Com os resultados obtidos, organizámos palestras para escolas e outros tipos de intervenções. Descobrimos que é muito fotogénico e que tem faces escondidas que resolvemos na altura baptizar de "ionic expressions of sodium chloride", seguindo a moda de Davidson. Não fizemos uma pesquisa exaustiva das suas propriedades físicas e químicas dado que a informação disponivel na Web tem crescido exponencialmente nos últimos tempos. Apenas coligimos alguns tópicos e sobretudo compilámos ideias que podem ser o ponto de partida para projectos ligando a Ciência à expressão artística, à literatura, poesia, música, história e indústria. No fundo, ligando-a à preservação do nosso património cultural, à nossa sociedade e ao lançamento de novas ideias que fomentem o empreendorismo e a sua ligação à Universidade.

Neste texto inserimos também uma adaptação de um trabalho experimental "Purificação de um sal iónico", de autores desconhecidos, descrito num antigo manual de Introdução às Técnicas Laboratoriais de Química do $1^{\circ}$ ano de Engenharia Quimica do IST. Consideramos que este trabalho é muito interessante - dai a sua inclusão neste artigo.

Palavras chave: cloreto de sódio, crescimento de cristais, cristais "On the Rocks", microscopia química, fotografia científica, fotomicrografia, ciência e arte.

Key words: sodium chloride, crystal growth "on the rocks", chemical crystals, photomicrographs, micrographs, chemical microscopy, science and art.

\section{PreÂMBULO}

A Química é como a música: pode ser tocada de muitas maneiras, com notas que neste caso são as moléculas, os átomos, os iões, os electrões e respectivas associações. Pode ir de "pimba" a erudita. Pode ir de chata a muito criativa. Pode ter muito de inspiração e menos de transpiração, ou ao contrário. Pode-se oferecer, pode-se esconder e com certeza vender. Quer queiramos, quer não, ela é omnipresente nas nossas vidas, nas nossas mortes, em tudo quanto nos rodeia. Mesmo que se esconda atrás do molecular.

Foi assim que se escondeu Michael Davidson da Universidade da Flórida e as suas "Molecular Expressions"1 um autêntico tsunami de divulgação científica que está a revolucionar a web, e que faz todos os Coelhos

\footnotetext{
Centro de Química Estrutural e Departamento de Engenharia Química e Biológica

Instituto Superior Técnico - Av. Rovisco Pais, 1049-001 Lisboa

clementina@ist.utl.p
}

Brancos que percorrem a Ciência ${ }^{2}$ [1] saltarem fora das tocas e lançarem tudo quanto têm na gaveta, neste momento de uma forma um tanto caótica, à laia do velho ditado, "Em tempo de guerra não se limpam armas" .

Este artigo é dedicado ao Chefe, ao Professor Alberto Romão Dias. Enquanto lutava pela vida, lutávamos nós, num espaço virtual no "Overworld da Web", em defesa do trabalho dos últimos anos, o qual tivemos o prazer de Ihe mostrar, há algumas semanas, num período de falsas melhoras entre cirurgias: a química apresentada nas suas mais vivas cores, patentes nas reacções observadas, filmadas e fotografadas ao microscópio, sem a cosmética da luz polarizada, sem efeitos especiais. Ao dar-nos o privilégio de nos inserirmos no seu grupo de investigação, fez-nos despertar para a Química Inorgânica, nas suas vertentes de Química de Coordenação, Organometálica, Química dos Elementos, sempre valorizando a divulgação científica como forma de chegar aos alunos a quem protegia, respeitava e amava como se fossem seus filhos: aqueles que biologicamente nunca teve, mas que foram seus durante a sua presença no Técnico e que continuarão a sê-lo, durante as suas vidas. Em tempo de expressões, assim foram as impressões que neles deixou. Deixou-nos também a Lq [2] e outras obras, deixou-nos a semente do seu trabalho como pedagogo e investigador, numa imensa rede transversal de pessoas, de ciência, de conceitos, sem preconceitos, de filosofia de vida. Uma rede de cooperação, reforçando as nossas mútuas atracções e vencendo as nossas repulsões,cada um no seu lugar, mais acima ou mais abaixo, mas sempre estrategicamente colocado, num esforço conjunto como que numa imensa rede, a nossa rede como que cristalina. Assim a saibamos manter.

Romão Dias, com certeza perdurarás nas expressões da nossa cultura.

Para Alberto Romão Dias 


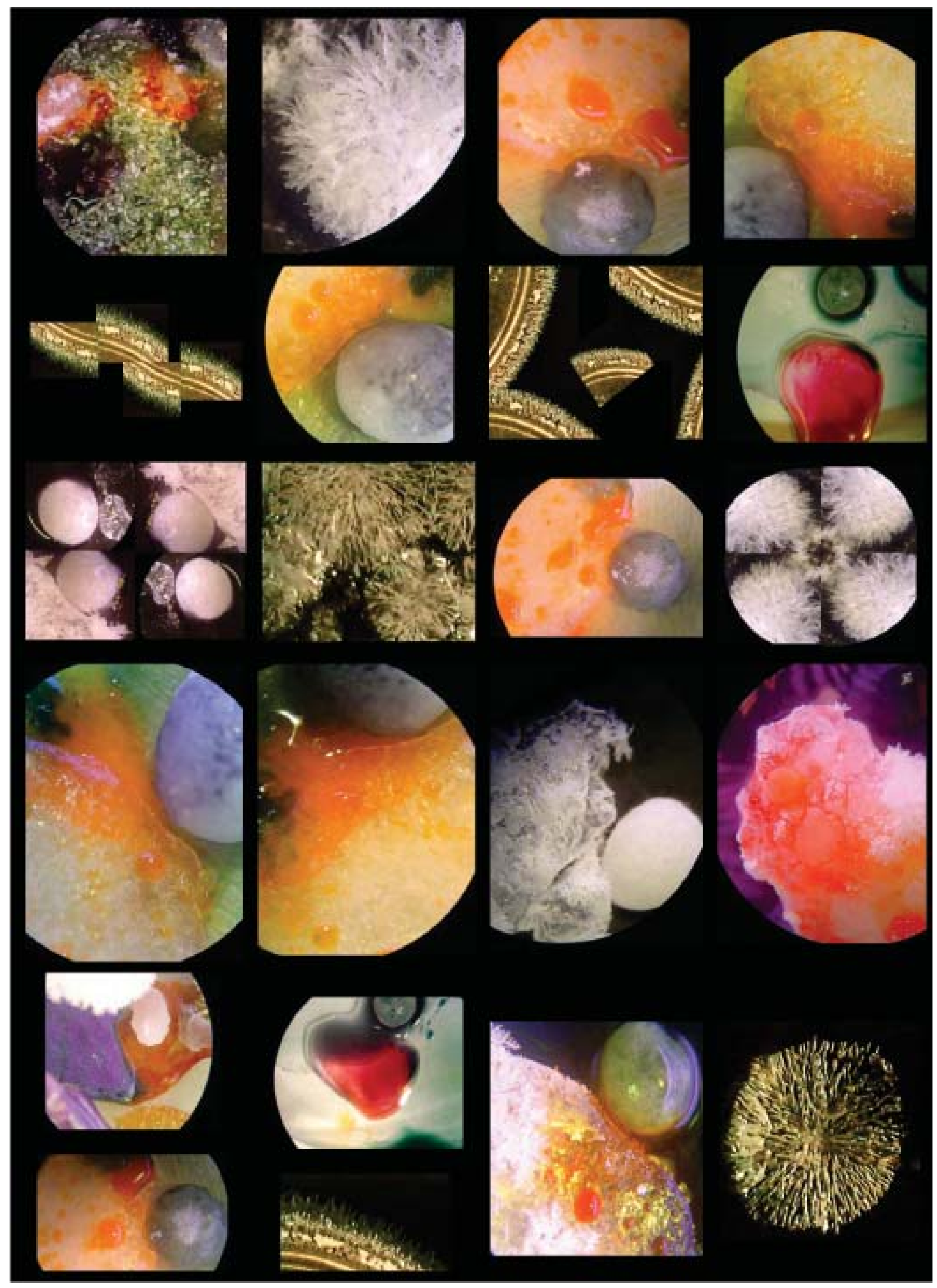

Figura 1 Da reacção à abstração: a Química nas mais vivas cores! 


\section{INTRODUÇÃO}

O cloreto de sódio daria um compêndio, ou vários, se alguém se dedicasse a escrever exaustivamente sobre as suas propriedades e aplicações. São aos milhares e crescem de forma vertiginosa os portais da Web que Ihe fazem referência, principalmente durante o corrente ano, reflectindo a vaga gigante de divulgação científica já referida $^{1}[3,4]$. Será com certeza uma árdua tarefa depurar toda a informação aí apresentada, posto que carece de revisão cuidada e é muito repetitiva.

O primeiro ponto que gostaríamos de realçar diz respeito aos principais motivos que levaram a esta pesquisa, resumidos no Quadro 1.
No Quadro 2 propõem-se outros temas de estudo que poderão tornar o projecto do sal mais envolvente e interdisciplinar: literatura nacional e estrangeira, temas de poesia, música, romance histórico, história, religião, educação visual, fotografia, cinema, arte, artes gráficas e suas aplicações industriais.

A primeira pesquisa que lhe sugerimos é literária e liga-se à obra de Colleen McCullough, ${ }^{3}$ "Os Favoritos da Fortuna” (Quadro 2). Embora seja preciso fôlego para a ler, pois que é muito volumosa, está bem traduzida, documentada e remonta à época conturbada de Caio Júlio César com a descrição das assembleias da plebe e toda uma epopeia que mostra bem a

Quadro 1 Razões pelas quais se deve estudar o cloreto de sódio

Enquadramento sócio - económico e cultural : situação geográfica de Portugal e os temas inspirados pelo mar, a principal fonte de sal: as praias, os barcos, os animais marinhos.
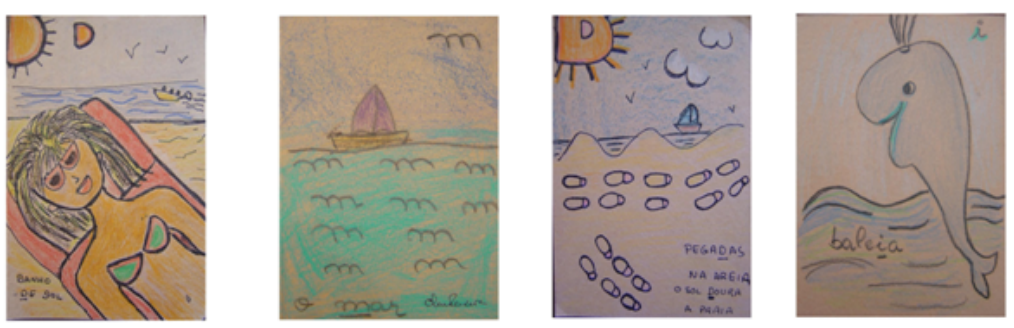

Um alfabeto muito criativo (APIST e $1^{\circ}$ ciclo do ensino básico) (Vide, Quadro 2).

O cloreto de sódio é extraído nas minas de sal gema e por evaporação da água do mar nas salinas. Sabes onde elas estão situadas no nosso País? Podes tentar procurá-las no mapa.

\section{Está presente no nosso quotidiano:}

É essencial na alimentação, embora não possa ser ingerido em excesso, (hipertensor); na gastronomia a flor de sal está a fazer furor, em Aveiro e em Tavira; é utilizado na preservação de alimentos (bacalhau,

peixes secos, preparação de presuntos e outras conservas).

É usado como medicamento: sais de banho, podologia, relaxante muscular, hipertensor, desinfectante, componente do soro fisiológico, tratamento da asma nas minas de sal gema de Loulé e do Salir no Algarve.

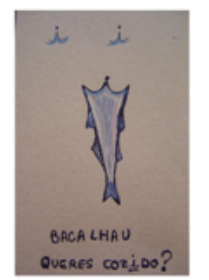

É usado na cosmética numa vasta gama de produtos e até em cremes hidratantes.

Tem numerosas aplicações na indústria química, sendo o composto de partida para a sintese de muitas outras substâncias.

Não é tóxico, é económico e muito acessível: logo, a sua química é sustentável, podendo ser apresentada a crianças muito novinhas, a partir dos cinco anos de idade: APIST, Quadro 2.

Representa a classe dos sais iónicos anidros, permitindo abordar muitos conceitos de Química Geral, ligação química, ligação iónica, ciclos de Bom-Haber, estrutura cristalina, diagramas de fases, regra das fases, formação de eutécticos, diagramas de solubilidade e sua variação com a temperatura, etc..

O crescimento de cristais e a cristalização são muito acessíveis, feitos por evaporação, podendo ser experimentalmente implementados nas escolas e até em casa, em kits de brinquedo. A versatilidade dos hábitos cristalinos do $\mathrm{NaCl}$ toma-o um bom exemplo para a introdução de conceitos relativos à cristalografia e à engenharia de cristais.

influência marcante da civilização romana na nossa cultura e maneira de ser. Como muita gente sabe, a palavra salário deriva do latim Salarium e a estrada através da qual se transportava o sal utilizado na antiguidade para o pagamento de ordenados era a Via Salária - uma espécie de autoestrada da época que cortava transversalmente a "península da bota", partindo do centro de Roma (vide plantas da cidade na mesma obra) ligando-a aos portos do Piceno, na costa leste.

A nossa pesquisa leva-nos depois para a Idade Média e para o tempo das cruzadas, das ordens militares religiosas, os Hospitalários, Cavaleiros de Malta e Os Templários, nas lutas com Saladino em Jerusalém, tema abordado nas obras de Juliette Benzoni (série Os Cavaleiros) $)^{4}$ e muitas outras obras: citem-se, por exemplo, as de Walter Scott e a série os Reis Malditos de Maurice Druon. Todo este enquadramento que se propõe relaciona-se com a designação de cristais malteses que aparece frequentemente nas publicações versando sobre cristalização e crescimento de cristais e também em tratados de medicina, associados a certas doenças detectadas pela análise da urina ao microscópio: a cruz de malta foi a designação que alguém remotamente escolheu para um defeito cristalino resultante da inclusão de moléculas de solvente em cristais, como se pode observar nas fotomicrografias da Figura 2 e no Quadro 2. De facto essa cruz assemelha-se mais à cruz de Pátea, e, como o leitor poderá constatar, as cruzes de Malta, de Pátea e de Cristo (introduzida por D. Dinis no século XIV e usada nas nossas caravelas) estão completamente misturadas na Web, o que mostra bem a confusão que aí grassa. Voltando ao tema do sal: será que os cristais de $\mathrm{NaCl}$ com a cruz inspiraram o design da cruz de Pátea? O sal era muito utilizado como medicamento e desinfectante e os monges da Idade Média eram bem conhecidos como curandeiros. Deixamos-lhe este tema para pesquisar e para observar as cruzes dos monumentos que abundam no nosso País, como, por exemplo, a verdadeira cruz de Malta no Convento das Maltezas, sede do Centro Ciência Viva de Estremoz; o Convento de Cristo em Tomar da Ordem dos Templários. São apenas dois casos e muitos mais irá com certeza descobrir, fazendo turismo cá dentro. 

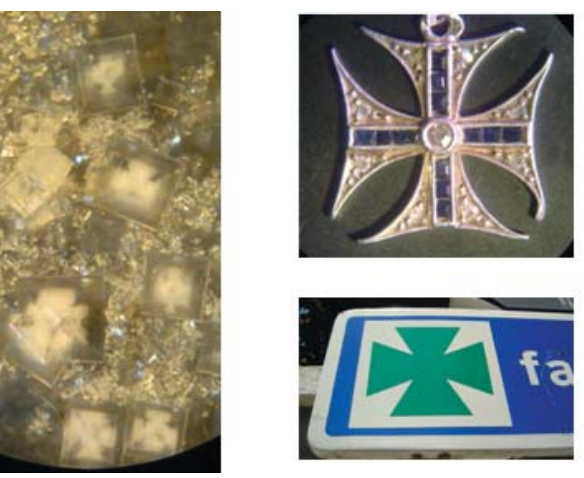

A primeira imagem mostra os cristais tabulares "malteses" de cloreto de sódio, fotografados com lupa binocular estereoscópica, exibindo uma cruz erradamente designada de cruz de malta, designação essa que, apesar de incorrecta, se tornou comum ${ }^{5}$. O mesmo símbolo aparece na cruz das Farmácias e na fotografia central, numa jóia de ouro branco com aparas de diamantes e safiras azuis, fotografada com uma lupa estereoscópica. Ambas se parecem mais com a cruz de Pátea. À direita, a porta do castelo de Belmonte, exibindo a Cruz de Cristo. A História de Portugal, os Descobrimentos (1500-1815), as cruzadas, os Castelos, os Conventos, os Pelourinhos todos contêm muitos destes motivos. Sugere-se também a procura da presença do sal nas obras de Fernando Pessoa, David Mourão Ferreira, António Gedeão (Lágrima de Preta), na Canção do Mar interpretada por Dulce Pontes, numa canção interpretada por Amália Rodrigues e Vinicius de Morais: o sal das minhas lágrimas de amor encheu o mar, que existe entre nós dois pr'a nos unir e separar. Esta leva-nos ao Brasil e daí a todos os Países de expressão Portuguesa.
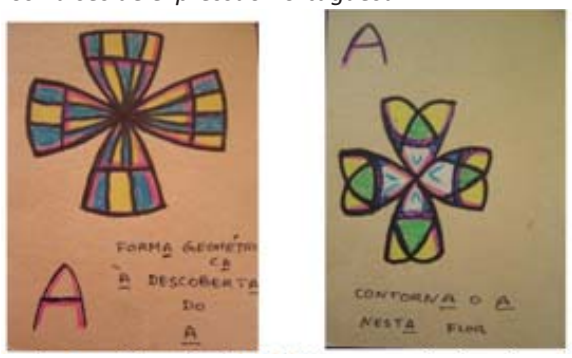

"Descobre a letra A no desenho ou, a partir da letra, faz o desenho. Podes tentar fazer desenhos a partir de todas as letras e números e construir um alfabeto diferente. O sal é o símbolo da hospitalidade e da amizade, porque o seu sabor é indestrutivel" Homero.

"O sal é o símbolo da incorruptibilidade uma vez que o termo "aliança de sal" traduz uma relação com Deus que não pode ser destruída", citação da Bíblia.

As designações "Beco (e Padrão) do Chão Salgado", em Belém, Lisboa, correspondem ao local onde se erigia o palácio do Duque de Aveiro, D. José de Mascarenhas, executado em 1759 juntamente com os Távoras, acusados de conspirarem contra D. José I. O seu palácio foi destruído e o solo foi salgado para que nada aí crescesse. Também as cinzas dos executados foram lançadas ao Tejo, no local onde começa o mar salgado.

Uma outra referência histórica é o movimento de protesto desencadeado por Ghandi, na Índia, em 1930 (Marcha do Sal, contra o imposto colonial sobre o sal), bem documentado no filme "Ghandi".

No título do filme "Sangue, Suor e Lágrimas", o sal é a substância comum aos três fluidos do organismo.

No infantário da APIST, cruzes da cruz de Pátea, inspiradas nos cristaís tabulares malteses

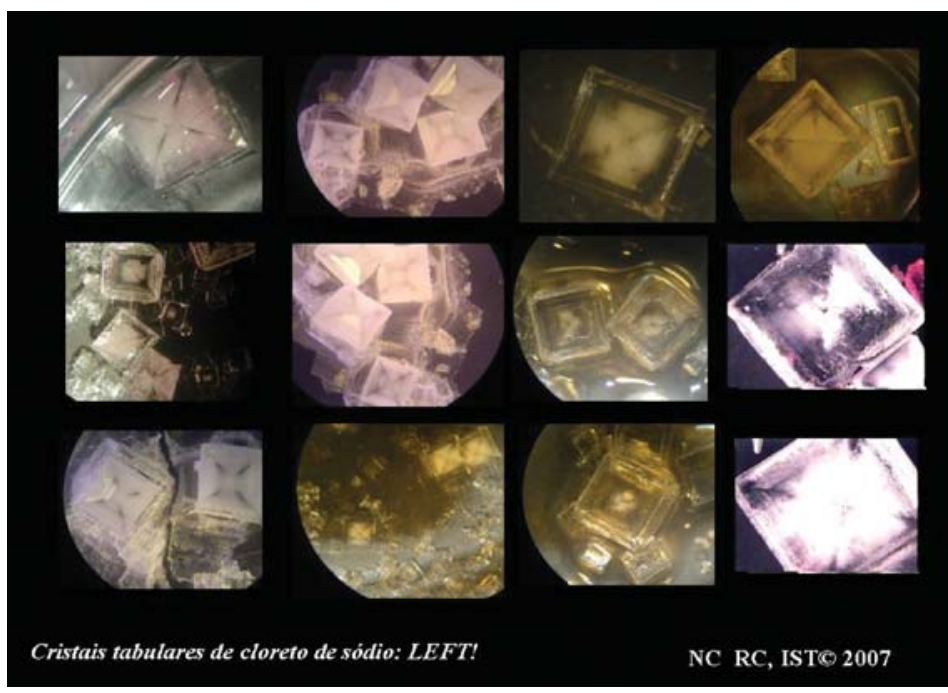

Figura 2 Fotomicrografias de cristais iónicos de $\mathrm{NaCl}$ quase todos malteses [3]
As fotomicrografias da Figura 2 foram obtidas com ampliação de 10X em lupa estereoscópica. Alguns cristais apresentam as faces arredondadas já com sinais de envelhecimento por terem permanecido no frigorífico durante três meses. Outros foram esquecidos e deixados a evaporar até à secura numa sala com ventilação de extracção muito forte, daí o trocadilho com a designação LEFT (Licenciatura em Engenharia Física Tecnológica) $[3,5]$.

\section{ALGUNS TÓPICOS SOBRE O CLORETO DE SÓDIO}

O cloreto de sódio encontra-se na $\mathrm{Na}$ tureza bastante puro e cristalino, constituindo o mineral halite, mais vulgarmente designado por sal-gema. Este pode ser transparente, translúcido e ainda apresentar diferentes tonalidades devido à presença de inclusões: branco, acinzentado, rosa, avermeIhado, laranja, violeta, azul, verde ${ }^{1}[4]$. A sua exploração mineira é então feita a partir destes depósitos subterrâneos de origem sedimentar, antigos lagos ou veios de água salgada (por exemplo, nas minas do Salir e outras, no Algarve, na Polónia, etc.). Porém, a sua principal proveniência é da água do mar, da qual é um dos constituintes maioritários (Tabela 1): cerca de $35 \mathrm{~g}$ de $\mathrm{NaCl} / \mathrm{Kg}$ de água [4]. (Esse teor pode atingir valores muito elevados, por exemplo, cerca de $300 \mathrm{~g} / \mathrm{l}$ no Mar Morto). Nestes casos, a exploração é feita a céu aberto e em grande escala nas salinas, por evaporação natural ao sol e ao vento (Aveiro, Figueira da Foz, reserva do Sapal no Algarve, reserva do Samouco no Montijo, Salt Lake no Utah (EUA), etc.).

Em 2002 a produção mundial atingiu 219 milhões de toneladas, sendo os principais produtores os Estados Unidos $(40,3)$, a China $(32,9)$, a Alemanha $(17,7)$, a Índia $(14,5)$ e o Canadá $(12,3)[4]$

O vulgar sal das cozinhas ou sal de mesa é constituído em cerca de $99 \%$ (em massa) por cloreto de sódio, $\mathrm{NaCl}$, e diversos componentes, alguns dos quais em quantidades vestigiárias. Entre estes encontram-se algumas impurezas associadas ao seu processo de extracção e substâncias propositadamente incluídas na sua constituição, 
designadas por aditivos, que the meIhoram as propriedades nutricionais, de processamento industrial e armazenagem. Actualmente o mercado oferece uma vastíssima gama de produtos para fins culinários, com imensos suplementos alimentares e diferindo ligeiramente na sua composição e granulometria. No nosso País, destaca-se a flor de sal, que tem sido bastante divulgada, fazendo concorrência nos mercados de gastronomia gourmet.

Entre os aditivos mais frequentes encontra-se o iodo, na forma de iodeto de potássio $(\mathrm{KI})$, iodeto de sódio (Nal) ou iodato de potássio $\left(\mathrm{KIO}_{3}\right)$, como fonte de iodo para a prevenção de Distúbios de Deficiência de lodo (DDI) que se encontram associados, por exemplo, a problemas de bócio, abortos prematuros e deficiências mentais no ser humano. A dose recomendada de iodo para um adulto é de $0,15 \mathrm{mg} /$ dia. O teor de iodo presente no sal de mesa comercializado varia entre $20 \mathrm{e}$ $60 \mathrm{mg}$ por $\mathrm{kg}$ de produto final.

Tabela 1 Composição aproximada da água do mar [6]

\begin{tabular}{|l|l|l|l|}
\hline Espécie & Concentração/mol. ${ }^{-1}$ & Espécie & Concentração/mol. ${ }^{-1}$ \\
\hline $\mathrm{Cl}^{-}$ & 0,55 & $\mathrm{Na}^{+}$ & 0,47 \\
\hline $\mathrm{SO}_{4}{ }^{2-}$ & 0,028 & $\mathrm{Mg}^{2+}$ & 0,054 \\
\hline $\mathrm{HCO}_{3}{ }^{-} / \mathrm{CO}_{3}{ }^{2-}$ & $2,3 \times 10^{-3}$ & $\mathrm{Ca}^{2+}$ & 0,010 \\
\hline $\mathrm{Br}^{-}$ & $8,3 \times 10^{-3}$ & $\mathrm{~K}^{+}$ & 0,010 \\
\hline $\mathrm{F}^{-}$ & $7 \times 10^{-5}$ & $\mathrm{Sr}^{2+}$ & $9,1 \times 10^{-5}$ \\
\hline $\mathrm{H}_{3} \mathrm{BO}_{3}$ & $4,3 \times 10^{-4}$ & & \\
\hline
\end{tabular}

Diversos aditivos têm sido utilizados como anti-aglomerantes ou agentes anti-caking: o carbonato de magnésio foi o primeiro composto a ser utilizado para esse fim (1911) e mais recentemente são usados os complexos ferrocianeto de sódio $\mathrm{Na}_{4}\left[\mathrm{Fe}(\mathrm{CN})_{6}\right]$ (menos de 100 ppm), ferricianeto de potássio $\mathrm{K}_{3}\left[\mathrm{Fe}(\mathrm{CN})_{6}\right]$, alumino-silicato de sódio, silicato de magnésio, fosfato de cálcio e outros. Estas substâncias permitem reduzir o teor em humidade, evitando a colmatação e melhorando as propriedades de fluxo de transporte no processamento industrial. Com efeito, sendo o $\mathrm{NaCl}$ uma substância já de si levemente higroscópica, esta afinidade pela humidade vem reforçada no sal pela presença de contaminantes com propriedades similares: o cloreto de magnésio, substância deli- quescente, e o cloreto de cálcio, muito higroscópico.

As soluções aquosas de cloreto de sódio puro são transparentes. Todavia, quando dissolvido em água, o sal de cozinha forma uma solução ligeiramente turva devido à presença dos agentes retardadores da humidade à base de alumino-silicatos, os quais formam uma suspensão, dada a sua baixa solubilidade.

O sal comercializado contém ainda uma pequena percentagem de carbonato e sulfato de magnésio, também presentes na água do mar. $A$ legislação impõe que para fins alimentares o teor de $\mathrm{MgCO}_{3}$ seja inferior a $1 \%$, recorrendo-se, para esta finalidade, a sucessivas lavagens.

Do ponto de vista de constituição química, não existe diferença entre sal grosso e sal refinado, variando apenas a granulometria, sendo este último obtido por trituração seguida

de peneiração do primeiro. Como é óbvio, a granulometria mais reduzida dissolver.

Mais recentemente surgiu a comercialização de sal "light" que consiste numa mistura 1:1 de cloreto de sódio e cloreto de potássio. $\mathrm{O}$ efeito do $\mathrm{KCl}$ caracteriza-se por ter um menor tempo de retenção no organismo humano em comparação com o $\mathrm{NaCl}$. Assim sendo, contribui para a diminuição da quantidade de água retida e para a melhoria do aspecto físico do consumidor. As designações "light" e "dietético" têm significados diferentes e a sua aplicação torna-se, por vezes, muito confusa. A primeira implica uma redução de $25 \%$ de calorias, no mínimo, em comparação com a versão convencional. Na segunda, há eliminação do sal refinado torna-o mais fácil de de um ingrediente. Por exemplo, alimentos dietéticos prescrevem-se aos diabéticos, suprimindo ou reduzindo o açúcar, enquanto que a restrição para hipertensos incide sobre o sal. Existem contudo produtos que pelas suas características são incluídos em ambas as designações ("light" e dietético), como é o caso da Coca-Cola "light", uma vez que não contém açúcares. A diminuição calórica num produto de consumo implica a redução de um ingrediente com apreciável valor calórico tal como hidratos de carbono, gorduras ou proteínas. Neste contexto, a designação de sal "light" não se refere a uma redução no valor calórico do produto, mas sim ao diferente efeito metabólico no organismo humano do $\mathrm{KCl}$ em relação ao $\mathrm{NaCl}$. Logo, a sua designação deveria ser dietético, dado que se suprime $\mathrm{NaCl}$, em favor de $\mathrm{KCl}$.

O cloreto de sódio é responsável pela troca de água das células com o meio que as circunda, por intermédio de fenómenos de osmose, ajudando-as a absorver nutrientes e a eliminar resíduos. Esta propriedade justifica o seu emprego na composição dos sais de banho e de outras soluções terapêuticas que se destinam a atenuar processos inflamatórios associados à retenção de água nos tecidos celulares (soluções salinas relaxantes para os pés e outras usadas em fisioterapia para combater dores nos ossos e articulações). A utilização ancestral das salmouras para preservar alimentos (o bacalhau! os presuntos!), baseia-se no mesmo princípio. O sal também tem um papel importante na contracção muscular. Todavia, está associado a problemas de hipertensão e do foro cardiovascular, daí que o seu consumo deva ser moderado. Por outro lado, a redução de $\mathrm{NaCl}$ também não pode ser excessiva, podendo provocar baixa de sódio no organismo, provocando alterações no sistema nervoso central, com alucinações, delírio, perda de consciência e outros sintomas.

Do total de sal actualmente extraído só cerca de $5 \%$ é utilizado no consumo humano. As restantes utilizações são das mais diversas: no fabrico de rações, na síntese de produtos químicos como fonte de sódio e cloro (produção de sódio, 
cloro, $\mathrm{NaOH}$, carbonato de sódio, bicarbonato de sódio, cloreto de cálcio, sulfato de sódio, cloratos, ácido clorídrico, etc.), nas indústrias do papel, cerâmica, cosméticos, estando ainda associado à utilização de corantes em têxteis, no fabrico de sabões, em metalurgia, etc.. Nas misturas frigoríficas gelo-sal, a formação de um eutéctico permite baixar a temperatura a $-21^{\circ} \mathrm{C}$ em aplicações laboratoriais controladas [4]. Em termos práticos e sem controlo do isolamento térmico do sistema e mistura das fases em equilíbrio o ponto de fusão baixa apenas a $-9^{\circ} \mathrm{C}$, permitindo derreter a neve: cerca de $51 \%$ da produção mundial de $\mathrm{NaCl}$ é usada para a remoção da neve na limpeza de estradas em países de clima frio. É ainda utilizado na desinfecção de piscinas, através de um processo electrolítico para a produção de cloro. Monocristais de $\mathrm{NaCl}$ de elevada pureza são usados no fabrico de janelas ópticas para espectrofotómetros UV-VIS e infravermelhos.

Enfim, como poderíamos nós viver sem um composto tão simples, que nem molécula tem para nos chatear, enfim, sem uma pitada de sal nas nossas vidas?

A CRistalização como tÉCNICA DE PURIFICAÇÃO E DE CRESCIMENTO DE CRISTAIS [1]

Monsieur de La Palice est mort Mort devant Pavie

Un quart d'heure avant sa mort Il était encore en vie!

Canção popular francesa, sec. XVI, conforme citação [7]

...E como partindo de cloreto de sódio se chega a cloreto de sódio...

Os termos cristalização, recristalização, precipitação física e química, confundem-se frequentemente na literatura.

Na linguagem corrente, quando se diz que algo está cristalizado, pretende-se afirmar que está "parado", preso numa forte "rede" que tolhe os movimentos, qual unidade constituinte dum cristal! Numa cristalização há essencialmente formação de cristais. (E pronto, sem

ambiguidades, cá está o nosso amigo francês.) A designação é por demais abrangente, embora se aplique com mais frequência a processos físicos. $\mathrm{O}$ termo recristalização implica que num dado processo se vai cristalizar de novo uma substância que já antes se apresentava cristalina e que, portanto, mantém a sua identidade química durante toda a operação: ao recristalizar sal de cozinha, cloreto de sódio, voltamos a obter de novo o cloreto de sódio, só que separado de impurezas, aditivos e com cristais de tamanho e hábitos diferentes [1]. A recristalização é assim entendida como um processo de purificação:

$$
\mathrm{NaCl} \text { (c)(impuro) } \rightarrow \mathrm{NaCl}(\mathrm{aq}) \rightarrow \mathrm{NaCl}(\mathrm{c})(\text { puro) }+ \text { impurezas(c/aq) }
$$

O termo precipitação também se pode tornar ambíguo, pois que também ele, fazendo parte do nosso léxico comum, é frequentemente utilizado: uma pessoa precipita-se quando toma decisões demasiado rápidas, quando anda demasiado depressa, quando "cai" no abismo. Quando se mede o grau de pluviosidade também se usa a designação de "precipitação": a fase líquida constituída por pequenas gotículas de água dispersas no seio de uma fase gasosa, o ar, atinge uma dimensão crítica superior a cerca de 10 micrómetros e começa a cair, pela acção da gravidade, "precipitando" na forma de gotas de chuva.

A precipitação, no caso restrito das soluções líquidas, implica que haja formação de uma fase sólida no seio da fase líquida, ou seja, há formação de uma substância insolúvel, ou muito pouco solúvel. Nas soluções aquosas os precipitados são frequentemente mais densos e obedecem às leis da gravidade, caindo. Porém, haverá casos em que este processo se torna muito moroso, dando origem a suspensões que deverão ser centrifugadas. Poderá ainda ocorrer a formação de um precipitado menos denso que ficará eventualmente suspenso na superfície livre do líquido. Existem ainda casos anómalos como a precipitação de hidróxidos e silicatos nos "jardins de sílica" que, embora mais densos, sobem, desafiando as leis da gravidade, pois estão ligados a fenómenos de osmose bem mais complicados de interpretar. $\mathrm{Na}$ precipitação física mantém-se a identidade química da substância. Pode ocorrer devido a uma diminuição de solubilidade provocada por abaixamento de temperatura, adição de um agente precipitante que induza a alteração da sua solubilidade, alteração da constante dieléctrica, etc.

$\mathrm{Na}$ precipitação química acontece mais do que isso e o processo vem dar origem a uma nova espécie química. Tal é o caso da formação de um sal duplo ou da vulgar reacção de dupla permuta iónica ou reacção de metátese, reacções exemplificadas no Quadro 3.

Aliás é exactamente com este último sentido que, em geral, se classificam as reacções em solução como reacções de precipitação. A formação de cristais e respectivo crescimento dependem de factores termodinâmicos (solubilidade) e cinéticos (nucleação e crescimento propriamente dito). Define-se solubilidade molar $S$ como a quantidade máxima de soluto expressa em moles que se consegue dissolver numa dada quantidade de solvente, até perfazer um litro de solução a uma dada temperatura. Nestas condições a solução diz-se saturada, e corresponde à situação de equilíbrio heterogéneo entre a fase sólida e a fase líquida. A constante termodinâmica deste equilíbrio designa-se por produto de solubilidade, $K p s$, e para efeitos do seu cálculo $S$ tem que vir expressa em mol. I $^{-1}$. Fora isso, pode ser expressa em quaisquer outras unidades, por exemplo, g/l ou outras equivalentes. Abaixo desta concentração limite as soluções dizem-se insaturadas e acima, sobressaturadas. O Grau de Sobressaturação (GS) permite medir o afastamento em relação ao equilíbrio $[1,8]$.

Ao iniciar uma cristalização é essencial ter uma ideia da solubilidade da substância com que se vai trabalhar e da sua variação com a temperatura. Consideram-se solúveis todas as substâncias de solubilidade superior a $10^{-2} \mathrm{M}$. Para substâncias pouco solúveis ou insolúveis, como é, por exemplo, o caso dos sais de chumbo, o equilíbrio atinge-se a concentrações muito baixas e, em geral, existem tabelados os valores de $K p s$ a $25^{\circ} \mathrm{C}$, que podem atingir valores tão baixos quanto $10^{-49}$ (sulfureto de prata), ou menos. 
Quadro 3 Exemplos de reacções de precipitação

Formação de um sal duplo pela adição estequiométrica dos sais componentes: Formação de schönite de magnésio e amónio

$\mathrm{MgSO}_{4} \cdot 7 \mathrm{H}_{2} \mathrm{O}(\mathrm{aq})+\left(\mathrm{NH}_{4}\right)_{2} \mathrm{SO}_{4}(\mathrm{aq}) \rightarrow\left(\mathrm{NH}_{4}\right)_{2} \mathrm{Mg}\left(\mathrm{SO}_{4}\right)_{2} \cdot 6 \mathrm{H}_{2} \mathrm{O}(\mathrm{s}) \downarrow+\mathrm{H}_{2} \mathrm{O}(\mathrm{l})$

Reacção de metátese ou dupla permuta iónica:

Soluções de iodeto de potássio reagem com soluções de nitrato de chumbo para formar nitrato de potássio em solução e iodeto de chumbo muito pouco solúvel, que precipita (precipitado amarelo canário).

$$
2 \mathrm{KI}(\mathrm{aq})+\mathrm{Pb}\left(\mathrm{NO}_{3}\right)_{2}(\mathrm{aq}) \rightarrow 2 \mathrm{KNO}_{3}(\mathrm{aq})+\mathrm{Pbl}_{2}(\mathrm{~s}) \downarrow
$$

Quando as substâncias são muito solúveis, normalmente não é indicado o seu Kps, mas sim a variação da solubilidade com a temperatura. Para a grande maioria dos sais comuns, a solubilidade aumenta com a temperatura. Porém, existem casos em que diminui (são exemplos sais com hidratos de diferentes estequiometrias como é o caso do sulfato de sódio deca-hidratado) e outros em que se mantém praticamente constante, como é o caso do cloreto de sódio: em $100 \mathrm{~g}$ de água dissolvem-se $34,2 \mathrm{~g}$ a $0^{\circ} \mathrm{C}, 35,9 \mathrm{~g}$ a $25^{\circ} \mathrm{C}$ e $38,1 \mathrm{~g}$ a $80^{\circ} \mathrm{C}$. A solubilidade é, como já se disse, uma propriedade termodinâmica que nos indica qual a quantidade máxima de soluto que uma solução comporta, a cada temperatura. Nada nos diz, porém, como essa substância se agrega: essa quantidade máxima distribui-se por grandes ou pequenos cristais? Por poucos ou muitos cristais? É a cinética da formação de cristais que nos dá essa resposta ou seja, a nucleação, o crescimento e as respectivas velocidades (Figura 3 e Quadro 4). Mesmo que a solubilidade varie pouco com a temperatura, esta afecta os parâmetros cinéticos, os quais são favorecidos pela sua diminuição.

As concentrações elevadas, ou seja, elevados GS, também afectam a cinética como se vê na Figura 3: o número e o tamanho dos cristais formados dependem muito da sobressaturação atingida. Segundo Pombeiro [8], a velocidade de nucleação $V_{n}$ (formação de núcleos cristalinos) começa por aumentar muito ligeiramente com o GS, passando depois a aumentar num regime exponencial. Por outro lado, a velocidade de crescimento dos núcleos cristalinos $V_{c}$, segundo o mesmo autor, é proporcional ao GS, o que é evidenciado pela equação de Von Weimarn [8]:

Para valores baixos do GS, a veloci-

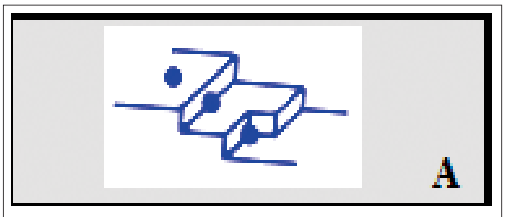
cópica.

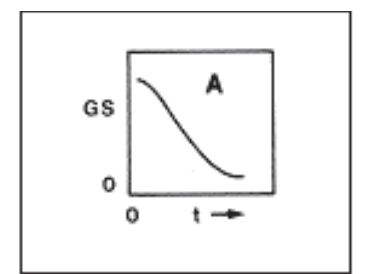

A - Grau de sobressaturaçao da solução $G S=\left(S^{\prime}-S\right) / S$ em função do tempo $\mathrm{t}$

S'- concentração do soluto em cada instante:

S- concentração da solução saturada, em equilíbrio, a cada temperatura. Quanto maior é o GS, menor é o tempo necessário para serem observados os primeiros cristais. dade de crescimento é superior à velocidade de nucleação: a tendência para o crescimento dos núcleos já formados é superior à de formação de novos núcleos. Para valores mais elevados de GS, a tendência para a formação de novos núcleos predomina sobre a de crescimento dos núcleos já formados. Em suma, baixos valores de GS conduzem a poucos cristais mas bem desenvolvidos, enquanto que valores de GS elevados conduzem a um número superior de cristais mas de dimensões reduzidas.

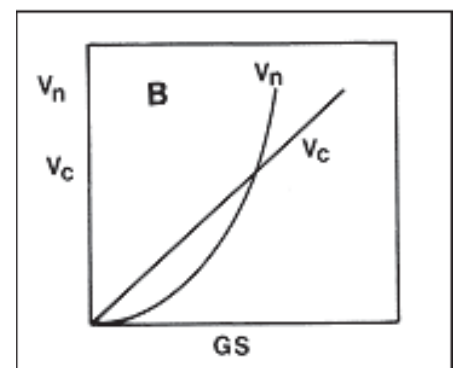

B - Funções hipotéticas de variação da velocidade de nucleação $V_{n}$ e da velocidade de crescimento $V_{c}$ com GS.

Figura 3 Alguns dos parâmetros que condicio nam o crescimento de cristais $[1,8]$

Quadro 4 As fases do crescimento de cristais (adaptado de [1])

I - Nucleação homogénea: Num ponto da solução homogénea (ou líquido), gera-se uma situação de instabilidade termodinâmica: GS>0, subarrefecimento, abaixamento de pressão, etc.. Esta condição de instabilidade constitui uma maneira de vencer a barreira de activação do sistema, à semelhança do que se passa numa reacção química. Formam-se então pares iónicos (no caso do $\mathrm{NaCl}$ ou substâncias iónicas) ou pequenos agregados de 3-4 unidades estruturais e em seguida cachos (clusters) que se dissolvem e refazem a cada instante, podendo coalescer, juntando-se a unidades estruturais semelhantes e na sua vizinhança.

Ao mesmo tempo estes agregados vão mudando de estrutura até minimizarem a sua energia de superfície. Quando atingem um tamanho mínimo crítico (1-10 nm, correspondente a cerca de 1000 unidades estruturais) passam a persistir na solução. A partir daí estes núcleos submicroscópicos crescem, e começam a formar a rede cristalina.

II - Crescimento: é favorecido pela presença de defeitos na rede cristalina em construção. Os deslocamentos (A) podem levar à formação de pontos estratégicos para "abrigar" o núcleo, impedindo a sua remoção e melhorando o seu desenvolvimento quando assenta em patamares, na intersecção de duas e de três faces, etc.. É controlado por fenómenos de transferência: de massa (soluto através da solução e para dentro da rede; solvente para fora desta); de calor, resultante da passagem para o estado sólido, etc.. Em solução estagnada a velocidade destes processos de difusão pode ser o factor limitativo da cinética de crescimento dos cristais.

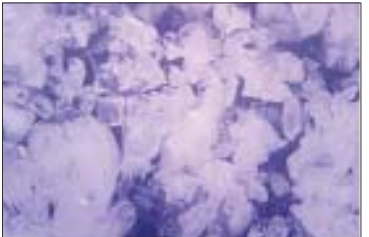

À direita: Instantâneo de vídeo mostrando a dissolução do $\mathrm{NaCl}$ observada numa lupa estereos-

III - Interrupção do crescimento: pode ser motivado por se ter atingido o equilíbrio correspondente à solução saturada: estas condições correspondem ao esgotamento dos nutrientes $(\mathrm{GS}=0)$ - na solução deixa de haver excesso de soluto que possa passar à fase sólida. O crescimento também pode parar pela criação de gradientes de concentração persistentes, quando a difusão é muito lenta. Daí fazer-se frequentemente o crescimento de cristais não em repouso, mas com fluxo de nutrientes em torno de uma semente colocando-a, por exemplo, numa mesa rotativa. Técnicas mais recentes de crescimento de cristais a bordo de naves espaciais, em condições de microgravidade, permitem obter cristais mais perfeitos, pois são eliminadas as correntes de convecção associadas à formação de defeitos e o acesso aos nutrientes é igual em todas as direcções, o que evita o desenvolvimento de hábitos distorcidos. 
Crescimento de cristais de cloreto DE SÓDIO

A preparação de cristais depende do fim em vista e das características que se pretendem obter no produto final.

Podemos purificar o sal por recristalização, sem nos interessar o seu tamanho e hábito cristalino - é o que acontece na produção industrial de granulado: obtêm-se cristais anédricos (sem forma geométrica definida) de baixo teor em água para melhorar as propriedades de fluxo. Mas também podemos desejar grandes cristais muito puros, para aplicações em espectroscopia, em que o hábito cúbico é privilegiado, para facilitar o corte na preparação de janelas ópticas. Neste projecto a nossa opção foi associar a purificação ao crescimento com defeitos cristalinos, i.e., a produção de malteses. Na Figura 4 podem-se observar cristais de $\mathrm{NaCl}$ de hábitos diferentes, todos desenvolvidos pela mesma técnica de evaporação lenta, na presença de modificadores de hábito, adicionados em quantidades muito pequenas - apenas uma pitada no sal em solução, neste caso, a ponta de uma micro-espátula. Em alguns casos, apenas alguns ppm são suficientes para que o sal mostre as suas faces escondidas. A forma do recipiente também é importante: quando o crescimento é feito em copo de forma alta, com uma altura de líquido considerável, há tendência para formar cubos; em recipientes de forma baixa, como os cristalizadores, ou num simples tabuleiro pyrex de ir ao forno, com uma altura pequena de líquido, a formação de cristais tabulares é mais provável pois apenas podem crescer para os lados e não para cima. Podemos ainda observar cristais aciculares (whiskers) de $\mathrm{NaCl}$ obtidos pela adição de álcool polivinílico ${ }^{6}$; cristais octaédricos obtidos na presença de formamida; tabulares hexagonais na presença de ureia; tornados dendríticos e brancos na presença de ferricianeto de potássio, e até mais eficazmente modificados com uma pitada de sal refinado. Embora se tenha tentado o crescimento de cristais por nucleação heterogénea, com rochas vulcânicas (Figura 6) e com a mesma composição da solução, em copo de precipitação alto, o facto é que o $\mathrm{NaCl}$ é um dos casos raros em que o suporte rugoso não tem qualquer influência. O estudo dos modificadores será publicado num outro trabalho [1 e refs. aí citadas, 9-11].

Nos casos analisados o método mais expedito para o crescimento de cristais de cloreto de sódio é sempre a evaporação do solvente, uma vez que a solubilidade varia muito pouco com a temperatura. Dissolve-se a amostra a quente, para a sua dissolução ser mais rápida, até condições próximas da saturação $(15 \mathrm{~g}$ de soluto $/ 45 \mathrm{~g}$ de água). A moagem prévia em almofariz também facilita a dissolução. Após filtração para separação das impurezas insolúveis, deixa-se evaporar lentamente e em repouso. Quanto mais lenta for a evaporação da água mais lento será o aumento do GS, pelo que se formarão menos núcleos e os cristais serão maiores (velocidade de nucleação inferior à velocidade de crescimento). Os resultados são muito melhores quando as preparações são feitas no Inverno, a temperaturas de cerca de $7^{\circ} \mathrm{C}$. No Verão pode ser usado o frigorífico, mas o abrir e fechar da porta cria perturbações que levam à formação de mais núcleos e cristais em maior número e mais pequenos. Quando o valor do produto iónico $\left[\mathrm{Na}^{+}\right]\left[\mathrm{Cl}^{-}\right]$exceder o produto de solubilidade $K p s$, isto é, quando a solução estiver sobressaturada, inicia-se então a precipitação e crescimento. A formação e o crescimento dos cristais são interrompidos pelo operador quando estes atingirem um tamanho conveniente e evitando ir até à secura, posto que isso levará à precipitação de todas as impurezas que se querem separar. Aliás, esse foi o "erro" cometido nos famosos cristais "LEFT!" na Figura 2. No final, os cristais são separados das águas-mães por nova filtração à trompa ou apenas com papel de filtro num funil de filtração e lavados com pequenas quantidades de água gelada, deixando-se a seguir a secar ao ar. Industrialmente o tamanho dos cristais do sal de mesa não deve ser muito grande, para reduzir a quantidade de água neles retida por aprisionamento mecânico [8] (água retida nos limites dos grãos cristalinos) e para facilitar o seu processamento industrial (ensacamento). Do mesmo modo, a formação dos malteses por retenção da água na rede cristalina é também evitada, posto que pode libertar-se mais tarde, por fenómenos de crepitação, devido à elevada tensão de vapor da água, dando origem à colmatação. $\mathrm{Na}$ literatura confundem-se muito os termos utilizados para a formação deste tipo de defeito cristalino, podendo ser referido como oclusão molecular e também inclusão [8].

Figura 4 Observação ao microscópio (lupa estereoscópica) de cristais de cloreto de sódio recristalizado a partir de amostras de sal de cozinha impuro e sais de banho

1 - Cristais tabulares malteses e cristais anédricos de cloreto de sódio com tartrazina (corante amarelo) e roxo, não identificado;

2 - Efeito do aumento do GS, com formação de cristais mais pequenos;

3 - Cristais cúbicos formados em copos de precipitação de forma alta;

\section{4 - Cristais recristalizados;}

5 a 7 - Formação de cristais dendríticos pela adição de sal refinado ou de ferricianeto de potássio;

8 - Cristais aciculares obtidos pela adição de ácool polivinílico;

9 - Cristalização com corante adicionado;

10 - Adição de ureia;

11 - Cristais octaédricos obtidos por adição de formamida. 
Nas utilizações espectroscópicas já referidas, privilegiam-se os monocristais de grandes dimensões, mas a sua pureza deve ser muito elevada e o teor em água muito reduzido, posto que a sua presença na rede diminui a transparência das amostras, diminuindo a qualidade dos cristais e a sua transmitância.

\section{Purificação e Crescimento de Cris- TAIS NO INFANTÁRIO DA APIST}

O trabalho de purificação de amostras de sais de banho e sal de cozinha impuro por recristalização permitiu introduzir conceitos relativos aos estados físicos da matéria, à noção de cristal, de ligação química, tendo sido feita também a viagem ao interior da matéria, e a observação ao microscópio (Figuras 5 e 6). Foi também explorada a construção de um alfabeto, fazendo desenhos a partir de letras e de números (Quadros 1 e 2) e também apresentado a crianças do $1^{\circ}$ ciclo do ensino básico. Ao contrário do que se possa à partida imaginar, a grande preocupação das crianças entre os cinco e sete anos é aprender a ler e escrever, sendo que qualquer proposta de actividade nesta área só poderá ser benéfica, aumentando o seu carácter interdisciplinar. A adaptação destas fichas está a ser realizada no primeiro ano do $1^{\circ}$ ciclo do ensino básico, orientada pelos respectivos professores.
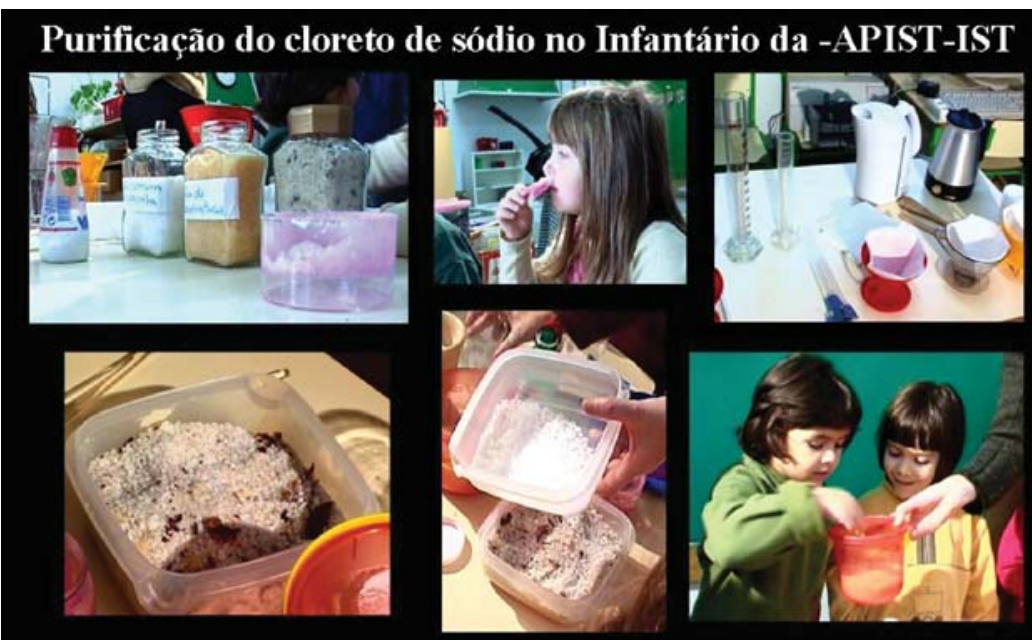

Sal de cozinha sujo; sais de banho coloridos; sal refinado; materiais usados na purificação do sal; as crianças observam as cores, a textura e experimentam o cheirinho dos sais de banho.
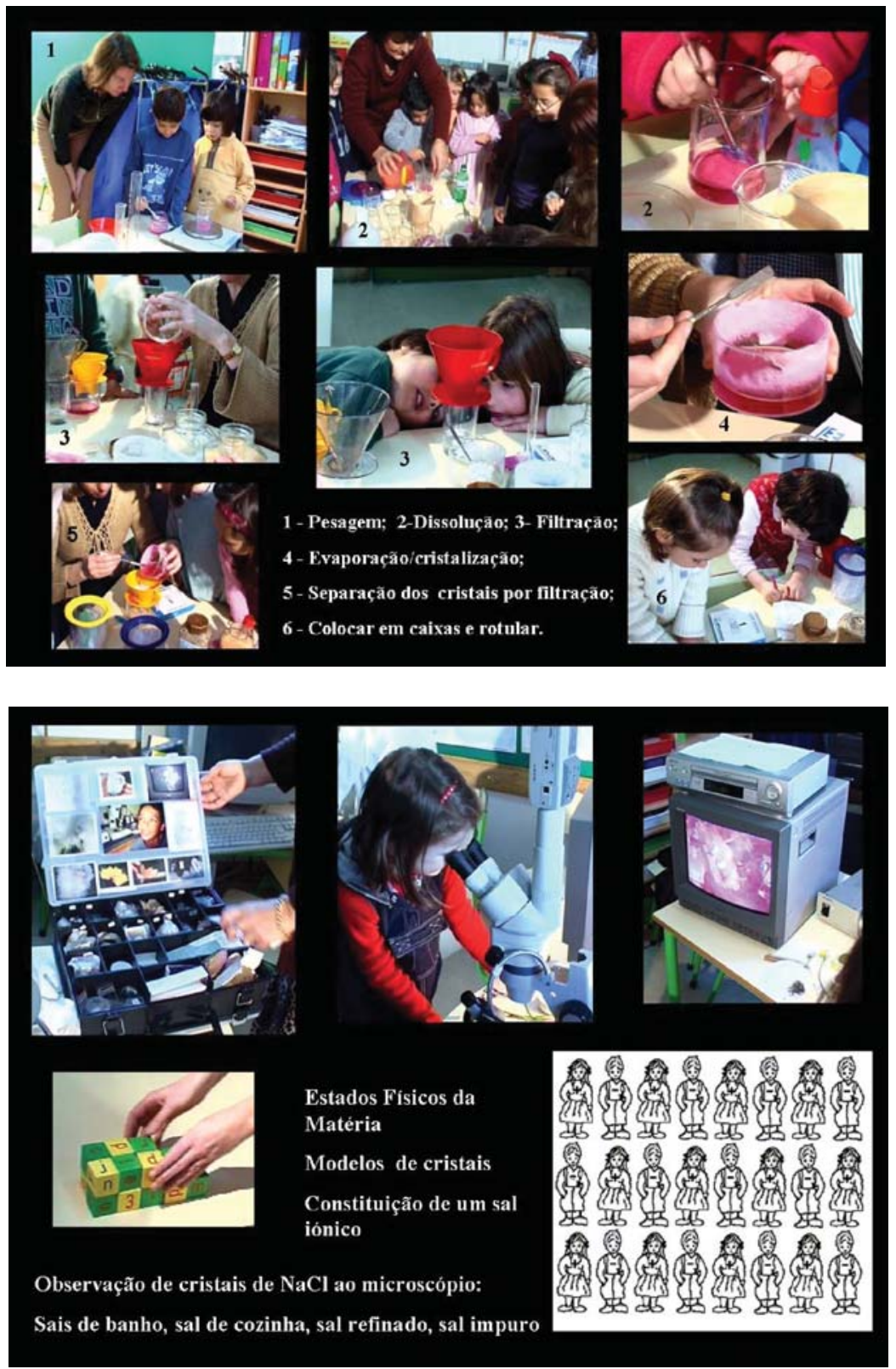

Figura 5 Purificação do cloreto de sódio (sais de banho e sal de cozinha). Na gravura 4 do slide do centro pode-se observar o efeito de "creeping" mencionado no texto 
Podemos observar o mundo à nossa volta tal como ele se nos apresenta. Isso não custa muito a fazer, basta manter os olhos bem abertos. Podemos depois passar a utilizar lupas, como fazem os ourives, os antiquários, os relojoeiros e todos aqueles que vêem mal, ou precisam de ver um pouco mais de perto - facilmente obteremos imagens ampliadas para o dobro, para o triplo...

Porém, graças ao desenvolvimento científico e tecnológico, podemos fazer muito mais ...
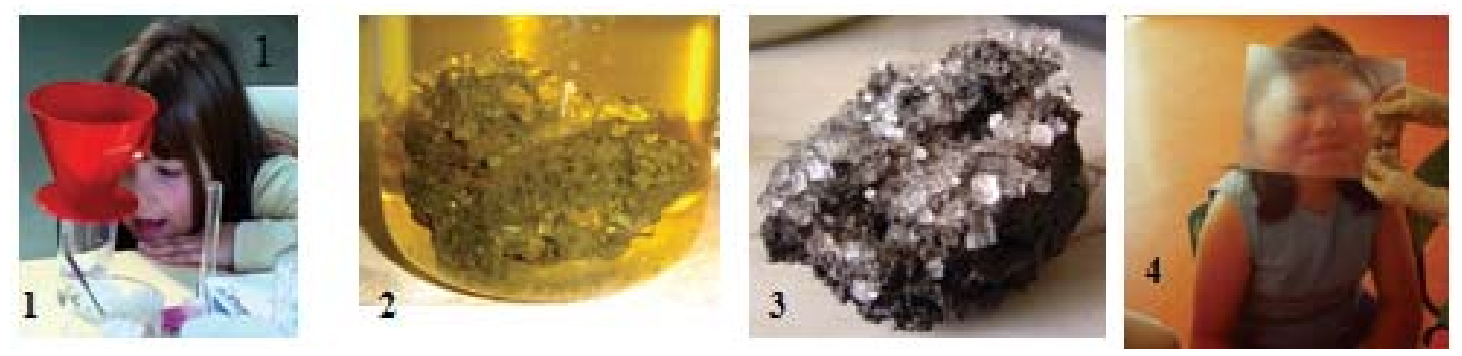

Basta utilizar um simples microscópio comum e a nossa visão dos objectos é ampliada até cem vezes o seu tamanho e por aí fora, 400, 500 vezes, até que perdemos as nossas referências e quase caímos na abstracção, se não soubermos o que estamos a observar.
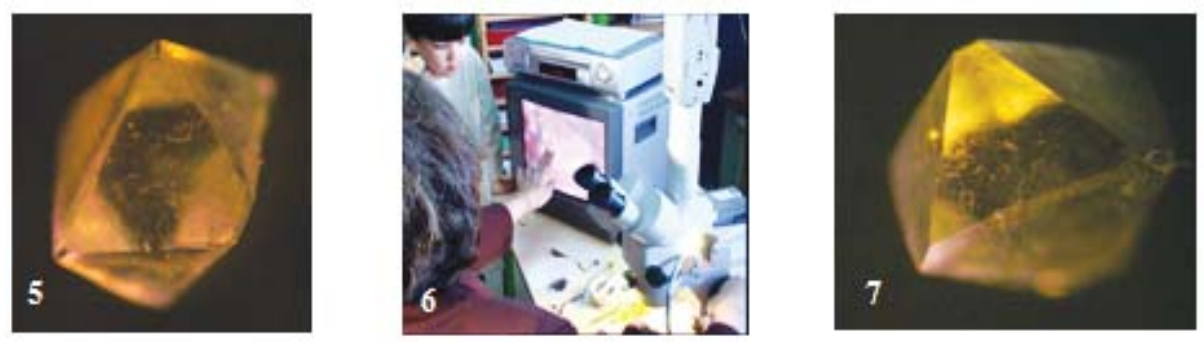

Se formos mais ambiciosos a nossa curiosidade levar-nos-á muito mais longe! Podemos penetrar nos puzzles das redes cristalinas dos cristais, ampliando-as $10^{5}$ vezes, cem milhões de vezes, passando do angström ao centímetro. Estes modelos de redes cristalinas são construídos a partir das estruturas obtidas pelos métodos de difracção de raios X. Nelas podemos localizar os iões sódio e cloreto na rede cristalina rigorosa do cloreto de sódio.

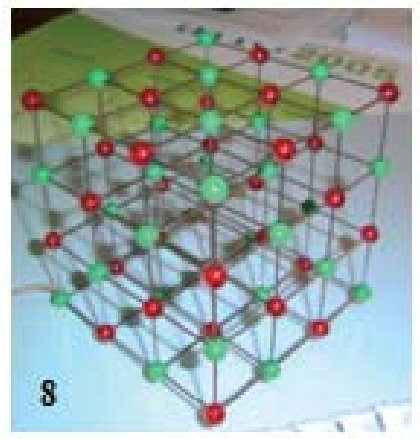

Rede cristalina rigorosa do cloreto de sódio, sistema cúbico

$\mathrm{Cl}^{-}$rede cúbica de faces centradas, CFC; seis iões $\mathrm{Na}^{+}$rodeiam cada anião $(\mathrm{NC}=6)$

$\mathrm{Na}^{+}$- CFC, preenchendo os interstícios octaédricos da rede dos aniões cloreto. $\mathrm{NC}=6$

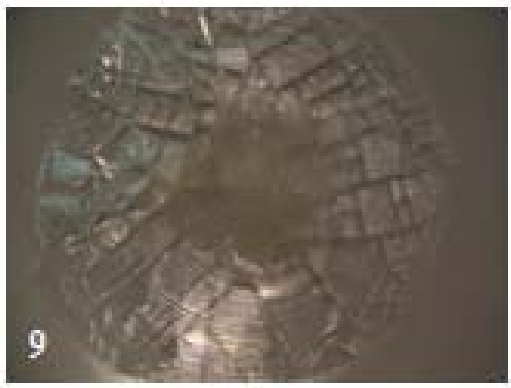

Modelo miniatura Beevers.

Figura 6 Viagem ao interior da matéria: o estudo do cloreto de sódio. 1-Experiência de purificação do sal no Infantário da APIST; 2,3-Crescimento de cristais de $\mathrm{NaCl}$ em rocha vulcânica; 4-Observando cristais com uma lente de Fresnel - Agrupamento Ribeiro Sanches, Penamacor; 5,7-Cristais de $\mathrm{NaCl}$ de hábito octaédrico ampliados 63X; 6-Observação de cristais de sais de banho coloridos com a lupa estereoscópica Nikon, acoplada a uma câmara digital Sony; 8-Rede cristalina do NaCl; 9-Sal amorfo, obtido por fusão/solidificação a $801^{\circ} \mathrm{C}$. 


\section{Notas}

1 Michael Davidson, Molecular Expressions: Images from the Microscope, http://micro.magnet.fsu.edu.Outros portais associados. Galerias de fotomicrografia, Ciência e Arte, tutoriais sobre óptica, história da microscopia e utilizações do Microscópio com luz polarizada para fotografar e filmar tudo quanto se possa imaginar, sempre com efeitos especiais: cerveja, cocktails, hamburgers, sementes de sésamo, vinhos, medicamentos, fármacos, Blue jeans, chips, meteoritos, metais, ligas e também alguns cristais, etc. Todas as fotografias ficam lindíssimas, fortemente coloridas mas indistintas, caindo no domínio da abstracção. Estabelecem links com todos quantos pedem autorização para a utilização de imagens, aumentando ainda mais a visibilidade do site. Também inclui pequenos vídeos de cristalização e tutoriais sobre cristais até à data ainda pouco desenvolvidas, mas preparam-se para uma grande ofensiva nesse campo. São sites de pendor fortemente comercial, que mostram como a ligação Universidade e Empreendorismo pode ser frutuosa, rentabilizando trabalhos de investigação, com reflexos positivos na Economia. Depois do "Power of Ten", Potências de Dez, deve ser dos trabalhos de maior relevância que se fizeram nos últimos anos. Em Julho de 2007, eram mencionadas 220000 entradas na Web, crescendo exponencialmente de dia para dia.

${ }^{2}$ O Coelho Branco da obra "Alice no País das Maravilhas" aparece neste artigo como uma primeira citação. Foi por convite do Professor Romão Dias e do Professor Jorge Calado que este artigo foi escrito.
Quando foi pedida ao Prof. Romão Dias a revisão do texto, perguntaram-lhe se deveria retirar o Coelho Branco. Deixem lá ficar o Coelho Branco. No fundo, sempre achou graça à irreverência na escrita.

${ }^{3}$ Escritora muito conhecida pela autoria dos "Pássaros Feridos", obra que deu origem à famosa série protagonizada por Richard Chamberlain, o padre de Bricassart, na Austrália.

${ }^{4}$ Infelizmente a obra de Juliette Benzoni tem muitos erros de tradução em Português, pelo que se alertam os professores e educadores para a sua correcção.

${ }^{5}$ Durante o seminário citado na ref. 3, o Professor Bernardo Herold alertou-nos para o facto da cruz de Malta ser diferente e com oito pontas. Sugere-se ao leitor a pesquisa na Web para encontrar a verdadeira cruz de Malta.

${ }^{6}$ Durante o seminário da ref. 3, fui alertada para a incorrecção desta designação - a designação correcta é poli(álcool vinílico). No entanto, como ela é usada na literatura, resolvi mantê-la.

\section{REFERÊNCIAS}

[1] C. Teixeira, "Os Cristais no Ensino e Divulgação da Química", Colóquio Ciências (Fundação Calouste Gulbenkian) 25 (2000) 20-36, disponibilizado na Web,http://zircon.dcsa.fct.unl.pt/dspace.

[2] Alberto Romão Dias e colaboradores, "Lq, Ligação Química", Instituto Superior Técnico, IST Press, 2006.

[3] C. Teixeira, "Ionic Expressions of Sodium Chloride": LEFT! What can we teach with these crystals? Seminários do Departamento de Engenharia Química e Biológica, DEQB, 29 de Junho de 2007

[4] Wikipedia: http://en.wikipedia.org/wiki/ Sodium_chloride e portais associados. Como a submissão de artigos na wikipedia não é sujeita a revisão, é necessário e conveniente confirmar a informação aí inserida.

[5] V. André, H. Diogo, N. Lourenço, C. Teixeira, "Água, quase tudo... e cloreto de sódio", 2004, Laboratórios de Química Geral, LEFT, IST, 2004-2007. Trabalho prático da cadeira de Química Geral de Licenciatura em Engenharia Física Tecnológica.

[6] A. Amaral, C. Correia, "Química", $12^{\circ}$ ano de escolaridade, Porto Editora, 1998.

[7] M. F. Camões, "A pureza química e o Senhor de La Palice", Química, Boletim da Sociedade Portuguesa de Química, 96 (2005) 69-71.

[8] A.J.L. Pombeiro, "Técnicas e Operações Unitárias em Química Laboratorial", Fundação Calouste Gulbenkian $2^{\mathrm{a}}$ Ed., Lisboa, 1991.

[9] C. Teixeira, "O Livro das Pedras", Instituto Superior Técnico, 1996.

[10] C. Teixeira, "Módulos de Experiências de Química", Instituto Superior Técnico, 2004.

[11] C. Teixeira, "Atlas de Crescimento de Cristais", Sais anidros, Instituto Superior Técnico, 2004

\section{Agradecimentos}

Projecto Ciência Viva-A Química Descobre a Criança - CV/VI/ID976

\section{Purificação e crescimento de cris- Objectivos do trabalho:} TAIS.

Esta secção foi adaptada de um antigo trabalho de Introdução às Técnicas Laboratoriais de Química. O interesse deste trabalho resulta da importância que o crescimento de cristais está a ter na área de Engenharia de cristais, com os estudos de co-cristalização, formação de polimorfos, formação de hidratos, alteração do hábito cristalino, etc..

\section{Actividade de LaboRatóRIO}

- llustrar os conceitos envolvidos na cristalização como técnica de purificação e de crescimento de cristais.

- Purificação do cloreto de sódio por recristalização: dissolução, filtração e precipitação.

- Observação do hábito e tamanho dos cristais obtidos por quatro técnicas de cristalização diferentes: i) precipitação por efeito do ião comum $\left(\mathrm{Cl}^{-}\right)$; ii) precipitação por utilização de mistura de solventes (água-etanol) com variação da constante dieléctrica e da solubilidade; iii) precipitação por evaporação lenta do solvente, à temperatura ambiente e iv) precipitação por evaporação lenta do solvente e a baixa temperatura, no frigorífico.

\section{TÉCNICA EXPERIMENTAL}

Reagentes e suas funções:

$\mathrm{NaCl}$ impuro (impurezas de origem culinária: pretende-se reciclar sal de mesa que tenha sido usado para fins culiná- 
rios; impurezas químicas adicionadas, $\mathrm{CaCl}_{2}$; também pode ser adicionado $\mathrm{MgCl}_{2}$, mas a separação é mais lenta; areia; as demais impurezas e aditivos mencionados na introdução teórica)

$\mathrm{HCl}(1 \mathrm{M})$ (para a produção de $\mathrm{HCl}(\mathrm{g})$ )

$\mathrm{NH}_{4} \mathrm{Cl}$ (para a produção de $\mathrm{HCl}(\mathrm{g})$ )

Etanol a 95\% (agente precipitante por alteração da constante dieléctrica)

Solução de $\mathrm{Na}_{2} \mathrm{CO}_{3}$ a $10 \%$ (m/v) (agente de precipitação do cálcio)

\section{Material de vidro e equipamento}

- Balança técnica

- Placa de aquecimento

- Frigorífico

- Hotte

- Lupa estereoscópica NIKON® com câmara digital SONY®

- Secador de cabelo

- Copo de precipitação de $100 \mathrm{ml}$

- Proveta de $100 \mathrm{ml}$ ou $50 \mathrm{ml}$

- Esguicho com água destilada

- Vareta de vidro

- 2 Kitasatos

- 2 Cadinhos filtrantes G4

- Borracha de suporte de filtração

- Trompa de vácuo

- Pipetas descartáveis ou pipetas de Pasteur

- 2 Tubos de ensaio

- 2 Cristalizadores

- 2 Papeis de filtro e elásticos

- Caixinhas de plástico

- Etiquetas
Procedimentos

* Pese, numa balança técnica, cerca de $15 \mathrm{~g}$ de cloreto de sódio impuro.

* Adicione a esta amostra cerca de 50 $\mathrm{ml}$ de água destilada e aqueça até dissolver a maior quantidade possível, deixando as impurezas insolúveis em suspensão.

* Deixe a solução arrefecer ligeiramente e filtre-a à trompa em cadinho G4: deste modo eliminará impurezas que sejam insolúveis a quente.

* Para eliminar o catião $\mathrm{Ca}^{2+}$, precipite-o sob a forma de carbonato de cálcio $\left(\mathrm{CaCO}_{3}\right)$. Para isso adicione gota a gota (com agitação) ao filtrado obtido no ponto anterior, solução de $\mathrm{Na}_{2} \mathrm{CO}_{3}$ a $10 \%(\mathrm{~m} / \mathrm{v})$. Pare a adição de solução de carbonato de sódio quando deixar de observar turvação da solução: isto significa que todo o ião $\mathrm{Ca}^{2+}$ existente estará precipitado. Para confirmar o fim da precipitação, filtre um pouco da solução de $\mathrm{NaCl}$ à qual adicionou $\mathrm{Na}_{2} \mathrm{CO}_{3}$, e junte mais umas gotas da solução de carbonato de sódio. A não formação de precipitado garante a inexistência de ião $\mathrm{Ca}^{2+}$. Separe o precipitado por filtração à trompa utilizando um cadinho G4.

* O excesso de ião carbonato introduzido no passo anterior é agora eliminado por adição à solução de $\mathrm{HCl}$ concentrado, até $\mathrm{pH}$ bastante ácido, com aquecimento. Observe a liberta- ção de $\mathrm{CO}_{2}$.

* Divida em três partes a solução que acabou de filtrar.

* Numa das partes, num tubo de ensaio, faça borbulhar cloreto de hidrogénio gasoso, preparado pela adição de ácido sulfúrico concentrado sobre cloreto de sódio ou cloreto de amónio (esta segunda versão é mais eficiente). Esta operação deve ser feita numa hotte.

* A outra das partes, também em tubo de ensaio, adicione lentamente etanol até observar o aparecimento de um precipitado. Para induzir o aparecimento do precipitado esfregue com uma vareta de vidro as paredes do tubo de ensaio.

* A última das partes deve ser dividida por dois cristalizadores: um, coberto com um papel de filtro, identificado, e posto num local onde possa permanecer em repouso e de preferência onde não ocorram grandes variações de temperatura; o segundo deve ser colocado destapado no frigorífico, identificado e deixado em repouso. A temperatura do frigorífico deve ser regulada de forma a evitar a congelação das soluções $\left(\approx 5^{\circ} \mathrm{C}\right)$. Logo que observe cristais desenvolvidos nestes dois últimos cristalizadores, recolha-os por filtração, lave-os com pequenas quantidades de água gelada e etanol, seque-os a frio e guarde-os em caixinhas rotuladas após observação ao microscópio.

\section{Purificação de um Composto lónico - Folha de Resultados E observações}

Equação química do passo em que juntou o $\mathrm{HCl}$ :

Equação química do passo em que juntou carbonato de sódio:

Equação química do passo em que preparou cloreto de hidrogénio gasoso:

Anotação da forma e tamanho dos cristais:

a) Quando borbulhou $\mathrm{HCl}$ gasoso

(obtém-se um precipitado microcristalino, devido ao aumento da concen- tração do ião cloreto, e ao deslocamento do equilíbrio pelo efeito do ião comum)

b) Quando adicionou etanol.

(Pretende-se demonstrar o efeito da alteração da constante dieléctrica do solvente; friccionar o tubo de ensaio com uma vareta de vidro permite despoletar a nucleação)

c) Quando deixou a evaporar lentamente.

(Obtêm-se cristais tabulares malteses.
Há sempre a ocorrência de "creeping", formação de cristais pequenos que "trepam" pelas paredes do cristalizador).

d) Quando colocou no frigorífico.

(Obtêm-se cristais tabulares malteses, maiores e em menor número, mas demoram muito mais tempo a cristalizar; também se observa a redução do "creeping").

e) Qual o processo que considera mais eficaz para a obtenção de cristais de $\mathrm{NaCl}$ ? 


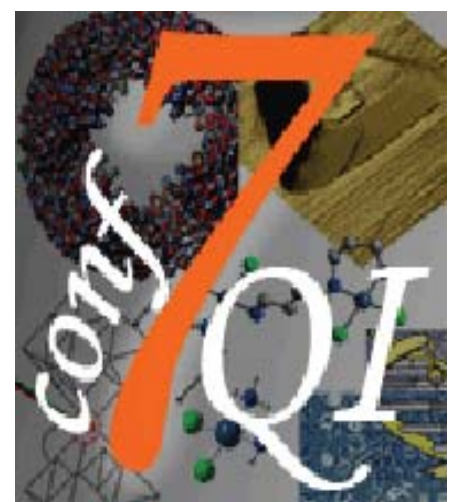

A $7^{a}$ Conferência de Química Inorgânica, a reunião bi-anual da Divisão de Química Inorgânica da Sociedade Portuguesa de Química, irá decorrer nos dias 30 de Novembro e 1 de Dezembro de 2007, no Hotel Cinquentenário em Fátima.

A Química Inorgânica tem actualmente uma abrangência cada vez maior, pois a sua relação com outras Ciências Básicas e Ciências Aplicadas, cresceu de forma vertiginosa nos últimos anos. Não se tendo escolhido um tema específico para a Conferência, pretende-se, no entanto, evidenciar os temas de interface da Química Inorgânica com a Biologia, a Medicina e as Ciências dos Materiais nas suas vertentes mais diversas. Assim, escolheram-se como plenaristas estrangeiros, Robert Hider, Professor de Química Medicinal (School of Biomedical Health Sciences, King's College London, Reino Unido) e Eugenio Coronado, Professor de Química Inorgânica-Materiais Moleculares (Instituto de Ciencia Molecular, Universidad de Valencia, Espanha). A conferência conta ainda com mais quatro plenaristas nacionais: Alice Pereira do Departamento de Química e Bioquímica da Faculdade de Ciências e Tecnologia, Universidade Nova de Lisboa, Eulália Pereira do Departamento de Química da Faculdade de Ciências, Universidade do Porto, Helena Nogueira do Departamento de Química da Universidade de Aveiro e Maria Paula Marques do Departamento de Bioquímica da Faculdade de Ciências e Tecnologia, Universidade de Coimbra. A Comissão Científica escoIherá ainda, entre os resumos submetidos, alguns trabalhos para apresentação oral; os restantes trabalhos submetidos à Conferência serão apresentados na forma de painel.

A $7^{a}$ Conferência de Química Inorgânica destina-se a investigadores que desenvolvem trabalho de investigação na área da Química Inorgânica Pura e Aplicada e em áreas interdisciplinares relacionadas. As conferências organizadas pela Divisão de Química Inorgânica têm também como objectivo divulgar e promover o interesse por esta área, principalmente aos investigadores mais jovens, desde estudantes de pré-graduação aos de pós-graduação, pelo que se convidam todos os participantes a incentivar esta iniciativa junto dos seus colaboradores mais novos. Os preços de inscrição são, por isso, bastante convidativos.

O programa científico da Conferência será semelhante ao de conferências anteriores, com início por volta das 11 horas do dia 30 de Novembro (6 $6^{a}$ feira) e terminando por volta das 18 horas do dia 1 de Dezembro (sábado).

No $1^{\circ}$ dia da Conferência realizar-se-à uma sessão especial em memória do Professor Alberto Romão Dias, Professor Catedrático do Instituto Supe- rior Técnico, membro dinamizador da Sociedade Portuguesa de Química, eminente professor e cientista de Química Inorgânica, nomeadamente na área da Química Organometálica. Esta sessão será organizada pelo Professor Carlos Romão do Instituto de Tecnologia Química e Biológica, Universidade Nova de Lisboa.

Informações mais pormenorizadas sobre a Conferência estão disponíveis em http://www2.fc.up.pt/7confQI/

Reserve desde já na sua agenda as datas da $7^{a}$ Conferência de Química Inorgânica. Contamos com a participação de todos os Investigadores nestes dois dias de discussão e reflexão de temas na área da Química Inorgânica e suas interfaces.

P’la Comissão Organizadora

Cristina Freire

REQUIMTE,

Departamento de Química, Faculdade de Ciências, Universidade do Porto

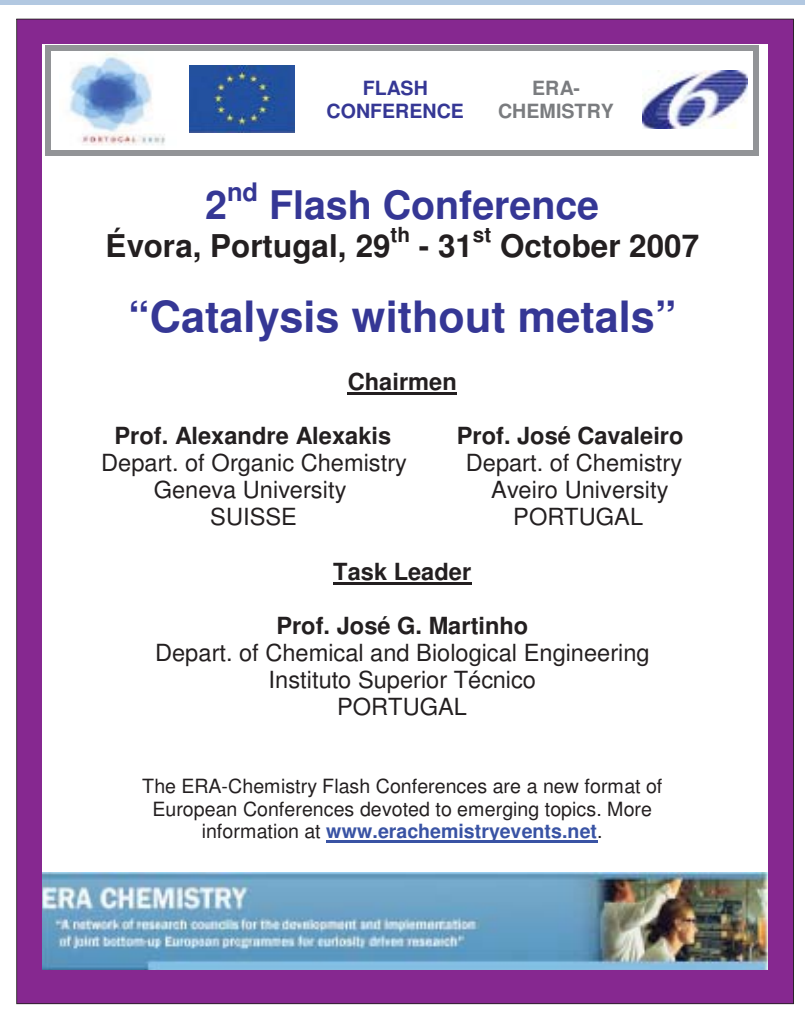

